\title{
Do we need changes in the organization of training in the hernia treatment in Poland? A survey on the acknowledgment of the recommendations of international hernia societies by surgeons
}

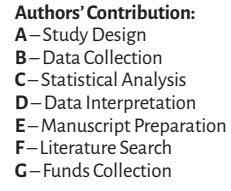

F-Literature Search

\author{
Kryspin Mitura ${ }^{1 \mathrm{ABCDEF}}$, Stanisław Dą̧browiecki ${ }^{2 \mathrm{ABDE}}$, Maciej Śmietański ${ }^{3 \mathrm{DEF}}$, Andrzej Matyja ${ }^{4 \mathrm{ADEF}}$ \\ 'Department of Ceneral Surgery, Municipal Hospital in Siedlce; Department Head: Kryspin Mitura MD, PhD \\ ${ }^{2}$ Department of Nutrition and Dietetics, Nicolaus Copernicus University in Toruń, Medical College in Bydgoszcz; \\ Department Head: Asst. prof. Cezary Popławski MD, PhD \\ ${ }^{3}$ Department of Ceneral Surgery, Hospital in Puck; Department Head: Asst. prof. Maciej Śmietański MD, PhD \\ ${ }^{4} 15 t$ Department and Clinical Ward of Ceneral, Oncological and Castroenterological Surgery, Jagiellonian University Medical College in \\ Krakow; Dlepartment Head: Prof. Piotr Richter MD, PhD
}

Article history: Received: 11.04.2017 Accepted: 26.07.2017 Published: 31.10.2017

ABSTRACT: In the therapy of an inguinal hernia, there is a huge variety in the way of treating and the choice of surgical technique. Practice shows that the intraoperative improvisation and surgeons' own modifications of the original techniques have become part of routine procedure. No mandatory hernia registration system causes the actual detailed herniology status in our country remains unknown. The aim of the study was to summarize the results of a survey on knowledge of a hernia according to the standards developed by international hernia societies compared with everyday clinical practice. During the International Conference Hernia in Poland, which took place on 10 December 2016 in Zakopane we conducted an interactive session among 106 surgeons dealing with hernias. Surgeons responded to 66 questions about daily surgical practice and decision making in their centers, and 27 questions for the assessment of the world's latest treatment recommendations regarding groin hernias. The most common method of using the implant technique Lichtenstein, used by $91 \%$ of doctors. $20 \%$ of surgeons in planned operations in adult men routinely uses no mesh technique. Almost $80 \%$ of respondents do not apply TEP or TAPP. Only $45.7 \%$ of surgeons customize surgical technique to the patient. Only 7 of the 27 analyzed recommendation has been accepted by more than $90 \%$ of respondents. 9 of the 27 recommendations were approved by less than half of the surgeons. In the case of 11 recommendations, surgeons simultaneously failed to comply with these recommendations in daily practice. Deficiencies in the system of training and the underfunding of medical procedures cause insufficient TAPP/ TEP availability in Poland in an inguinal hernia. Improvement of the surgeons' knowledge on how to perform surgery for an inguinal hernia with access to a properly designed training can enhance the results of treatment of hernias in Poland.

\section{INTRODUCTION}

Thanks to the advances in evidence-based medicine, proven and efficient methods of treatment were identified for numerous surgical conditions. However, diverse management approaches and surgical techniques are still in use in the treatment of inguinal hernia $(\mathrm{IH})$ [1-6], despite the fact that $\mathrm{IH}$ repairs are among the most commonly performed surgeries [7]. Inadequate efficacy of tension repair techniques used in the past as well as non-compliance with the guidelines for tension-free techniques popularized at the turn of the $21^{\text {st }}$ century have led to a situation where the treatment of this pathology is quite commonly arbitrary. Due to the diversity of clinical cases encountered by surgeons during their practice, the treatment is often tailored with established methods being used as starting points. Practice shows that intraoperative improvisation and proprietary modifications of original techniques became elements of routine management [8]. Usually the distant outcomes of individualized management are not subject to any analysis which precludes any verification of the efficacy of that particular approach. Due to the absence of a coherent, obligatory hernia surgery registration system, the status of herniology in Poland remains unknown. Among others, this manifests in the absence of any data on the number of laparoscopic procedures; this absence is unprecedented on the European scale. Out of 10 European countries which had implemented a diagnosis-related group (DRG) classification system Diagnosis-Related Groups, Poland is the only country where the actual number of laparoscopic procedures cannot be determined [7]. More advanced surgical methods are not a common surgeon's choice due to the lack of additional reimbursement. The availability of sites providing treatment that complies with the current guidelines of international societies varies across the country. At the same time, the training system in place does not ensure sufficient conditions for reliably mastering the required skills with regard to different complementary techniques of surgical management of inguinal hernias.

\section{OBJECTIVE}

The objective of the study was to sum up the results of a survey on the surgeons' compliance with the recommendations of international hernia societies and to examine the everyday clinical practice with regard to the management of hernias. The results should help in determination of the degree of compliance to hernia management recommendations in Poland as well as in identification of potential limitations to a wider use of these recommendations.

\section{MATERIAL AND METHODS}

During the International Hernia Congress which took place on 10 December 2016 in Zakopane, an interactive session was held with the participation of 106 surgeons specializing in hernia treatment. 
Thanks to the use of state-of-the-art software (VoxVote), responses could be provided by the surgeons using their personal smartphones. Questions and possible answer variants were displayed on the phone screens. Individuals who decided not to use this option entered their responses on paper questionnaires. A total of 102 to 106 answers were provided to each question. The results were summarized for analysis and report.

Questions related to the treatment of inguinal hernia by open as well as laparo-endoscopic methods. Surgeons provided answers to 66 questions regarding the everyday surgical practice and decision-making processes at their sites as well as to 27 questions regarding current global recommendations for IH treatment.

The surveyed surgeons came from different regions of Poland, with the highest numbers coming from Małopolskie voivodeship $(\mathrm{n}=16)$, Mazowieckie and Lubelskie voivodeship ( $\mathrm{n}=10$ each) as well as Łódzkie, Śląskie, and Podkarpackie voivodeships ( $\mathrm{n}=9$ each). Each of the other voivodeships were represented by 2-7 physicians. Forty-eight surgeons were less than 35 years of age. Higher decade-based age groups (36-45, 46-55, 56-65) were represented by 14,27 , and 16 surgeons, respectively. One surgeon was older than 66 years of age. Forty-eight surgeons specialized in general surgery while the remaining physicians had not yet completed their specialization. Within the population of responders, a total of 28 surgeons performed surgeries in less than 25 patients each year, 40 surgeons performed surgeries in 26 to 50 patients each year, 29 surgeons performed surgeries in 51-100 patients each year while 9 surgeons performed surgeries in more than 100 patients each year. A total of 61 surgeons declared being skillful in the treatment of hernias while 21 surgeons declared being experts with this regard.

\section{RESULTS}

Despite the fact that all surgeons agreed with the statement that mesh techniques were preferred in the treatment of $\mathrm{IH}$, one in every five of them (a total of 21 surgeons) declared routine use of mesh-free techniques in elective surgeries in adult male patients. Another $31.4 \%$ of surgeons used no implants only when managing hernias in an emergency setting while only one half (48.6\%) of the surgeons used implants in all cases. Figure 1 presents the most common technique of implant-free surgical management of $\mathrm{IH}$ in situations where mesh implantation would be altogether impossible. In addition, the figure presents the surgeon's preference of pure tissue techniques in the imaginary scenario of the surgeon undergoing the surgery themselves.

According to the responders, Lichtenstein method is the most common method for the treatment of primary unilateral IH (91.3\%). When the method is inappropriate for any reason, $40.9 \%$ of surgeons treat IH using a mesh-free anterior approach while $27.6 \%$ make use of another implant-based anterior approach method (Fig. 2).

A vast majority of responders (87.6\%) agreed with the recommendation stating that surgeons should be aware of clinical characteristics of implantation materials being used. However, responses to a differently formulated question suggested that only $48.6 \%$ of surgeons routinely pay attention to physical specification of the mesh implant such as its porosity and weight. Macroporous mesh is used by a vast majority of surgeons $(92,3 \%)$ in young,

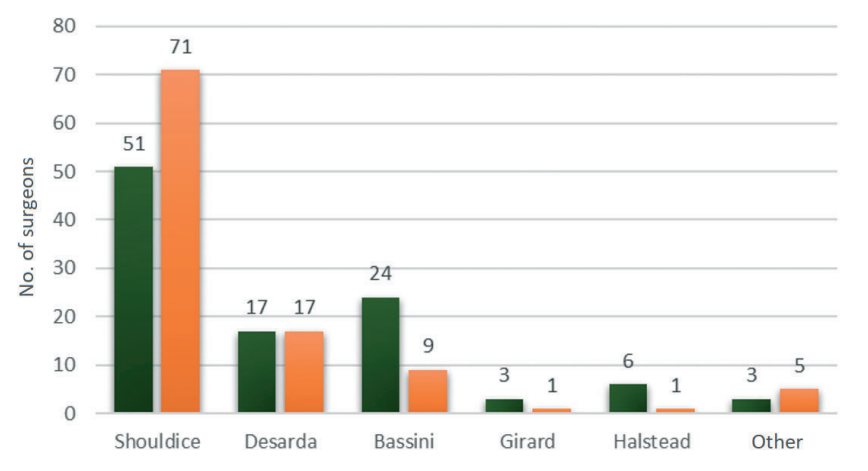

- When surgery is performed in patient $\mathbf{a}$ If the surgery was to be performed in the surgeon

Fig. 1. Type of mesh-free technique used when synthetic mesh implant can not be used $(n=103)$

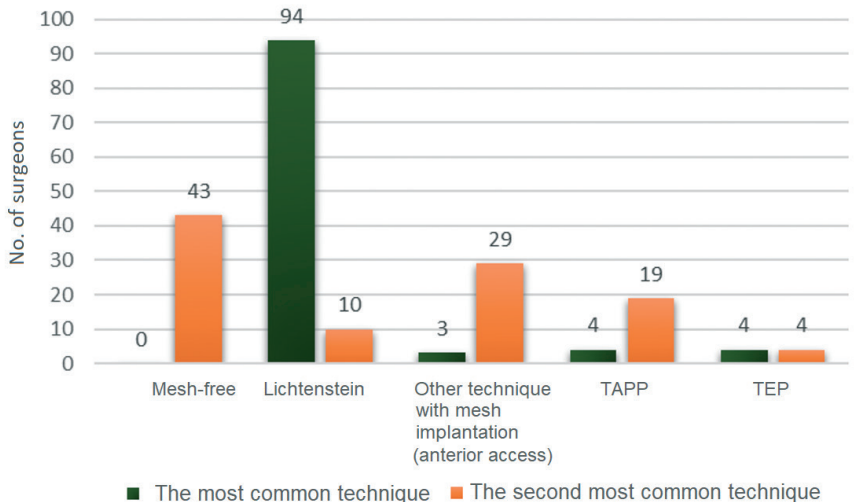

Fig. 2. Two most common techniques used in inguinal hernia repair surgeries $(n=105)$.

lean patients with small lateral hernias while more robust, heavier mesh is used in older, obese males with large direct hernia only by one half (50\%) of responders. At the same time, as many as $28.3 \%$ of , surgeons declare having no access to various types of mesh implants suitable for various techniques at the site of their affiliation.

Nearly $80 \%$ of responders used no laparo-endoscopic methods (TEP, TAPP). A similar percentage of surgeons does not use intraperitoneal onlay mesh (IPOM) for the treatment of abdominal hernias. This is probably associated with the surgical methods preferred within the surgical departments at the sites of their affiliation. In most responders' departments laparo-endoscopic procedures are not used in the treatment of inguinal or abdominal hernias (Fig. 3). The lack of knowledge of the laparo-endoscopic methods was also confirmed by the responses to cost-related questions, with the majority of responders being unaware of the approximate price of a mesh implant used in the TAPP procedure $(68 \%)$ or of the approximate price of mesh fixation devices (85\%). A positively surprising finding consisted in availability of various implants for surgical management of IH in as many as $3 / 4$ operating theaters. Three out of every four surgeons $(75.0 \%)$ declared taking up endo- and/or laparo-endoscopic methods should the reimbursement rates offered by the public payer be more beneficial. Only $8.7 \%$ of responders would not be interested in changing the surgical technique even if the reimbursement rates were higher. 
Tab. I. Recommendations acknowledged by a vast majority of the surgeons.

\begin{tabular}{|c|c|}
\hline RECOMMENDATION & $\begin{array}{l}\text { ACKNOWLEDGEMENT OF } \\
\text { RECOMMENDATION } \\
\text { (\% OF RESPONDERS) }\end{array}$ \\
\hline $\begin{array}{l}\text { Acquired, surgical and perioperative risk factors are recommended to be strongly considered since they are potentially modifiable and can } \\
\text { influence the type of repair performed. }\end{array}$ & 100 \\
\hline Anterior repair is recommended after a failed posterior repair. & 97 \\
\hline It is recommended that surgeons tailor treatments based on expertise, local/national resources, and patient- and hernia-related factors. & 96 \\
\hline Clinical examination alone is recommended for confirming the diagnosis of an evident groin hernia. & 94 \\
\hline $\begin{array}{l}\text { Although most patients will develop symptoms and need surgery, watchful waiting for minimal or asymptomatic inguinal hernias is safe since } \\
\text { the risk of hernia complications is low. Management decision is made between the surgeon and patient. }\end{array}$ & 92 \\
\hline $\begin{array}{l}\text { Discussions with patients about timing of hernia repair are recommended to involve attention to social environment, occupation and overall } \\
\text { health. The lower morbidity of elective surgery has to be weighed against the higher morbidity of emergency surgery. }\end{array}$ & 90 \\
\hline $\begin{array}{l}\text { During open surgery, planned prophylactic ilioinguinal nerve resection is not suggested since it does not reduce chronic pain incidence and it } \\
\text { increases postoperative sensory loss. }\end{array}$ & 90 \\
\hline
\end{tabular}

Tab. II. Recommendations acknowledged by not more than one half of the surgeons.

\begin{tabular}{|c|c|c|c|}
\hline \multirow[t]{2}{*}{ RECOMMENDATION } & \multicolumn{3}{|c|}{$\begin{array}{l}\text { ACKNOWLEDGEMENT OF } \\
\text { RECOMMENDATION } \\
\text { (\% OF RESPONDERS) }\end{array}$} \\
\hline & YES & NO & $\begin{array}{l}\text { DON'T } \\
\text { KNOW }\end{array}$ \\
\hline $\begin{array}{l}\text { Local anesthesia is recommended for open repair of reducible inguinal hernias provided surgeons/teams are experienced in local } \\
\text { anesthesia use and administering the local anesthetic. }\end{array}$ & 52 & 42 & 6 \\
\hline Mesh is recommended to be used in elective femoral hernia repairs. & 50 & 30 & 20 \\
\hline Patients are recommended to resume normal activities without restrictions as soon as they feel comfortable. & 48 & 48 & 4 \\
\hline In open mesh repair, administration of antibiotic prophylaxis in average-risk patients in a low-risk environment is not recommended. & 43 & 48 & 9 \\
\hline $\begin{array}{l}\text { From a cost-effectiveness perspective, day-case laparo-endoscopic inguinal hernia repair with minimal use of disposables is } \\
\text { recommended. }\end{array}$ & 40 & 25 & 35 \\
\hline $\begin{array}{l}\text { Immediate severe/excruciating postoperative pain raises the possibility of vascular or nerve injury. Early re-operation on the same } \\
\text { day is suggested to either exclude or manage these complications. }\end{array}$ & 25 & 55 & 20 \\
\hline General or local anesthesia is suggested over regional in patients aged 65 and older. & 18 & 60 & 22 \\
\hline
\end{tabular}

Other interesting findings were related to factors that determined the choice of the surgical technique. Less than one half of the responders declared that their treatment methods were selected on the basis of patient- or disorder-related factors (45.7\%). As many as $43.8 \%$ of responders used a single surgical method regardless of the disorder or patient's condition while another $10.5 \%$ declared that the choice of the treatment technique was made by their superiors.

Only $66.6 \%$ of surgeons acknowledged the claim that women with groin hernias are recommended to undergo laparo-endoscopic repair while only one half of the responders (50.0\%) acknowledged the claim that mesh is recommended to be used in elective femoral hernia repairs in women. Figure 4 presents inguinal hernia repair techniques preferred by the responders in female patients.

Only one half of the surveyed surgeons (50,0\%) agreed with the suggestion that patients may be recommended to resume normal activities without restrictions as soon as they feel comfortable. This is reflected by the postoperative recommendations given to patients as presented in Figure 5.

The survey questions were of dual character. On one hand, they pertained to the acknowledgment of EHS recommendations while on the other hand, they were aimed to examine the everyday clinical practice. The acknowledgment of individual EHS recommendations varied; part of these recommendations were fully acknowledged (Table I).
Similarly high acknowledge rates (79-96\%) were obtained for recommendations regarding hernia surgery trainings, namely the recommendation regarding experts surgeons carrying out resurgeries after failed repairs, the need for advanced training and requirements to be met by reference sites.

Recommendations for the use of endo-laparoscopic methods in IH surgery were acknowledged. Possibility of performing surgeries from both anterior and posterior approach as well as comparability of TEP and TAPP techniques were acknowledged (yes 49\%; don't know 48\%), as well as the use of TAPP/TEP for the repair of bilateral hernias, the need for laparo-endoscopic surgery in cases of hernia recurring after Lichtenstein surgery (and vice versa), and indications for endo-laparoscopic surgery as the method of choice. High doubts (yes 53\%; no 11\%; don't know 37\%) were raised by recommendation regarding mesh fixation in patients with large direct hernias (M3-EHS classification). However, the value of the above declaration was limited as only one in four responders had performed an endo-laparoscopic surgery within a period of 3 months preceding the survey.

Some EHS recommendations were acknowledged by less than half of the responders (Table II).

For some recommendations, finding one's own opinion was difficult for at least $20 \%$ of responders (Table III). 
It is interesting to study the consistence between the responders' declarations and actual surgical practice. Before the questions regarding recommendations, the survey contained slightly modified questions regarding the routine management methods. In some cases, the theory matched the practice, as in the case of 3D mesh implants; the responders both acknowledged the recommendation that these should not be used in anterior approach surgeries (86\%) and actually declared not using these implants (89\%). However, high discrepancies between acknowledgment of recommendations and routine management or opinions declared when questions did not specifically refer to any recommendations (Table IV).

Only $57.7 \%$ of surgeons declared that European recommendations for hernia treatment had or would have impact on their performance.

\section{DISCUSSION}

Therapeutic decisions in surgery must be made on the basis of both one's own experience and of the available scientific evidence. Due to the rapid progress of science and the increasing number of publications, surgeons find it increasingly difficult to pick from the abundance of data any particular information that might contribute to the improvement of individual treatment results . To this end, scientific associations make efforts to develop management guidelines for individual areas of medicine. Working teams established by these societies review current literature and after careful selection thereof determine sets of appropriate recommendation. Compliance with the recommendations of scientific associations allows the surgeons to provide treatment that is in line with the current best medical knowledge. In recent years, recommendations regarding IH management were developed by several leading surgical societies including European Hernia Society (EHS), International Endohernia Society (IEHS), and European Association of Endoscopic Surgery (EAES) [9-11]. As the result of their efforts, the international HerniaSurge team developed the first global set of recommendations for IH managements to be further assessed by surgeons participating in the EHS Congress in Rotterdam in 2016.

In Poland, distant outcomes of IH treatment remain unknown. The absence of an obligatory registry of IH surgeries and superficial reporting practiced within the health insurance system do not contribute to the reliability of data on the performed procedures. This has not changed for many years despite the fact that inguinal hernia surgeries are among the most common surgical procedures being performed in Poland [7]. An all-Polish conference with the participation of surgeons interested in IH treatment is an excellent opportunity to assess the surgeons' knowledge of the disorder, their decision-making processes, and their opinions on the current recommendations of international medical societies. The collected data may be used to identify areas that require corrective measures being taken with regard to the improvement of medical knowledge, trainings, as well as organization of the hernia management system in Poland.

The results presented in this study illustrate a significant discrepancy between the theoretical knowledge and the clinical practice of patients. In many aspects, surgeons acknowledged the recommendation claims while not complying with them in the treatment they provided. Contrary to literature reports regarding the safety

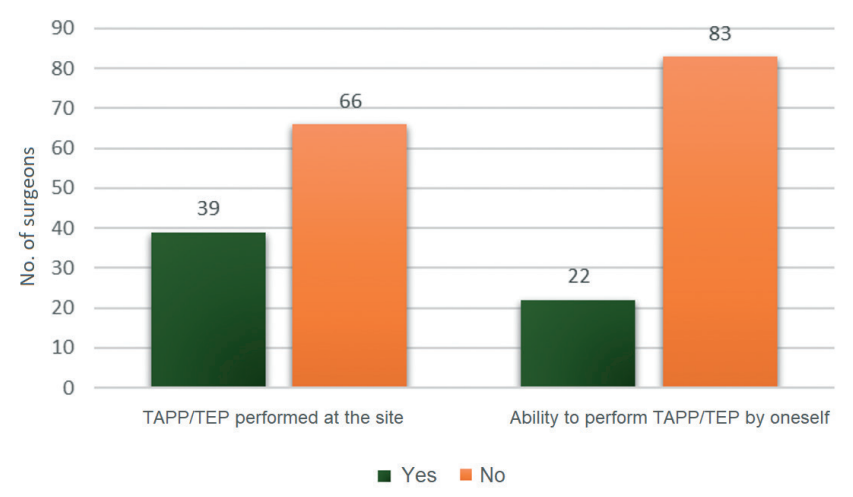

Fig. 3. The use of laparo-endoscopic method at the sites of affiliation of surgeons taking part in the survey and their own knowledge of how to use these methods $(n=105)$.

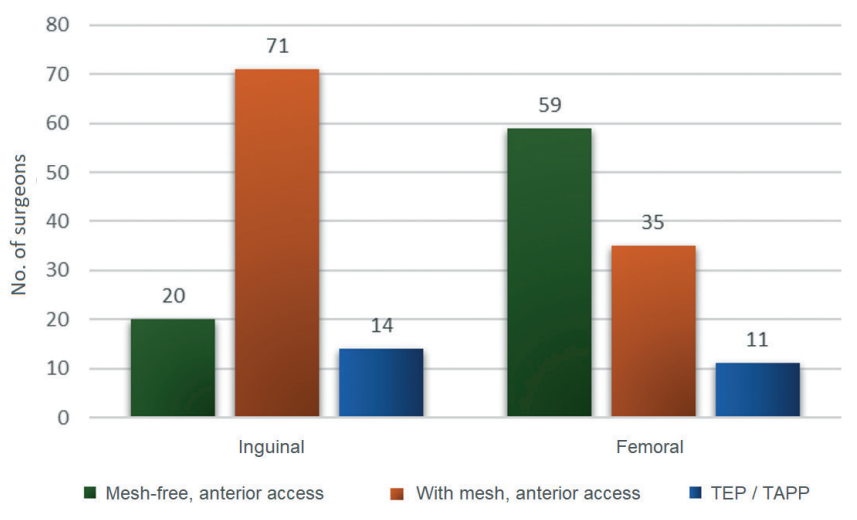

Fig.4. Methods for the treatment of inguinal hernia in female patients $(n=105)$.

of macroporous mesh implants in clean-contaminated environments, only less than one half of patients used mesh implants in both elective and emergency surgeries [12]. Other surgeons use mesh-free tension techniques while the Shouldice technique which is recommended in such cases is used by less than one half of the responders [13]. What's interesting, most surgeons pointed to the Shouldice technique when asked about the preferred method of undergoing mesh-free hernia repair as a patient. This suggests that despite the surgeon's conviction that the is technique is efficient, there is insufficient training with regard to the proper conduct of this surgery $[3,14]$.

Compliance with the recommendations requires that the surgeon tailors the method and the implanted material to the particular patient as well as to own experience. Unfortunately, due to the limited availability of synthetic mesh implants of various characteristics at medical sites and to the prevalent custom of one obligatory surgical technique being imposed to all surgeons within the site, patients are tailored to the site's surgical technique rather than the surgical technique being tailored to the patient. This is particularly evident in the case of laparoendoscopic methods. Despite the technique being favored by surgeons and despite the surgeons' will to master the TAPP and/or TEP in their clinical practice, the number of physicians able of skilfully performing such procedures is still too low. Even at sites where such procedures are being offered, not all the surgeons are capable of delivering this type of treatment. Even smaller is the number of surgeons for whom this technique is the primary operating method. One should keep in mind that 


\begin{tabular}{|c|c|c|c|}
\hline \multirow[t]{2}{*}{ Recommendation } & \multicolumn{3}{|c|}{$\begin{array}{l}\text { Acknowledgement of } \\
\text { recommendation } \\
\text { (\% of responders) }\end{array}$} \\
\hline & Yes & No & $\begin{array}{l}\text { Don't } \\
\text { know }\end{array}$ \\
\hline $\begin{array}{l}\text { From a cost-effectiveness perspective, day-case laparo-endoscopic inguinal hernia repair with minimal use of disposables is } \\
\text { recommended. }\end{array}$ & 40 & 25 & 35 \\
\hline $\begin{array}{l}\text { Use of so-called light weight meshes in inguinal hernia surgery (open and laparo-endoscopic) may have some short-term benefits } \\
\text { (reduced postoperative pain and shorter convalescence). }\end{array}$ & 56 & 10 & 34 \\
\hline $\begin{array}{l}\text { The use of open non-mesh repair in specific patients or types (e.g. young males with lateral hernia L1) of inguinal hernia as an } \\
\text { acceptable alternative to a Lichtenstein technique requires further studies. }\end{array}$ & 51 & 26 & 23 \\
\hline General or local anesthesia is suggested over regional in patients aged 65 and older. & 18 & 60 & 22 \\
\hline Mesh is recommended to be used in elective femoral hernia repairs. & 50 & 30 & 20 \\
\hline $\begin{array}{l}\text { Monofilamental large pore polyproplene mesh-based repair is suggested in emergent groin hernia surgery with a clean or clean- } \\
\text { contaminated surgical field. }\end{array}$ & 59 & 21 & 20 \\
\hline
\end{tabular}

Tab. IV. Discrepancies between the percentages of surgeons acknowledging the recommendations and actually complying with them in practice.

\begin{tabular}{|c|c|c|}
\hline Recommendation & $\begin{array}{l}\text { Practical } \\
\text { compliance (\%) }\end{array}$ & $\begin{array}{l}\text { Acknowledge- } \\
\text { ment of recom- } \\
\text { mendation } \\
(\%)\end{array}$ \\
\hline Clinical examination alone is recommended for confirming the diagnosis of an evident groin hernia. & 66 & 94 \\
\hline Hernia surgeons are recommended to be aware of the intrinsic characteristics of the meshes they use, & 49 & 88 \\
\hline $\begin{array}{l}\text { Pre- or perioperative local anesthetic measures like field blocks of the inguinal nerves and/or subfascial/subcutaneous } \\
\text { infiltration are recommended in all open groin hernia repairs. }\end{array}$ & 46 & 60 \\
\hline Day surgery is recommended for the majority of groin hernia patients provided adequate aftercare is organized. & 32 & 76 \\
\hline $\begin{array}{l}\text { In open mesh repair, administration of antibiotic prophylaxis in average-risk patients in a low-risk environment is not } \\
\text { recommended. }\end{array}$ & 30 & 43 \\
\hline $\begin{array}{l}\text { Use of the EHS classification system for inguinal hernias is suggested for the purposes of performing research, tailoring } \\
\text { treatments and performing quality audits. }\end{array}$ & 28 & 71 \\
\hline $\begin{array}{l}\text { Pragmatic resection of the ilioinguinal nerve and/or the iliohypogastric nerve is recommended if iatrogenic nerve injury occurs } \\
\text { or if the nerve(s) interfere(s) with mesh position. }\end{array}$ & 18 & 70 \\
\hline $\begin{array}{l}\text { Nerve anatomy awareness and recognition during surgery is recommended to reduce the incidence of chronic post- } \\
\text { herniorrhaphy pain. }\end{array}$ & 13 & 80 \\
\hline $\begin{array}{l}\text { Local anesthesia is recommended for open repair of reducible inguinal hernias provided surgeons/teams are experienced in } \\
\text { local anesthesia use and administering the local anesthetic. }\end{array}$ & 6 & 52 \\
\hline Patients are recommended to resume normal activities without restrictions as soon as they feel comfortable. & 5 & 48 \\
\hline
\end{tabular}

the survey was performed in surgeons who were particularly interested in the treatment of hernias, and therefore the situation may be much worse on the all-national scale. With the number of surgeons performing this type of surgeries being so small, it will be difficult to comply with numerous international recommendations such as those regarding the treatment of hernias in women, recurrent hernias following previous anterior repair, and bilateral hernias where TAPP or TEP constitute an inseparable element of comprehensive management [15-16]. Despite the requirement that all patients should obtain understandable and comprehensive information on the available treatment alternatives before any treatment is commenced, nearly one half of the surgeons fails to inform their patients about the possibility of undergoing laparo-endoscopic treatment. This is also confirmed by the fact that more than one half of the surveyed surgeons had never referred an $\mathrm{IH}$ patient to another surgeon or treatment site. Unfortunately, insufficient training in TAPP and TEP techniques combined with the conviction of laparo-endoscopic treatment being unprofitable is responsible for the limited access of the Polish patients to the state-of the art treatment methods. It appears that a systemic im- provement of appropriate skills resulting from obligatory trainings held as part of surgery specialization proceedings could improve the availability of these treatment methods in Poland [17-18]. At the same time, the cost effectiveness of laparoscopic methods which facilitate early recovery and recommencement of professional activity should promote the sites which offer this type of services [19]. What's interesting, day-case treatment is offered at a small number of sites despite the economic benefits of such a solution being evident $[20,21]$. One of the reasons may consist in the rare use of local anesthesia in anterior access IH repairs.

The reduction in the number of $\mathrm{IH}$ recurrences following introduction of tension-free methods turned the attention of surgeons to another aspect of the treatment, namely to the postoperative pain [22]. Despite the established management standard, the number of surgeons offering peri-wound injections as an efficient way of treating postoperative pain is still too low [23]. At the same time, high diversity is observed with regard to the handling of inguinal nerves, particularly as they collide with the implanted mesh. In such cases, the mesh should not be cut or trimmed as it is com- 
monly done since it may increase the incidence of recurrent hernias [24]. Therefore, analgesic management, appropriate selection of analgesia, appropriate local analgesia technique and the ability to identify and handle inguinal nerves are another areas in which trainings should be provided to the surgeons.

Of note in the survey results was the evident lack of surgeons' support for the recommendations regarding antibiotic prophylaxis as well as physical activity in the postoperative period. The recommended non-necessity of antibiotic prophylaxis is rejected by the surgeons on the basis of local conditions at their medical sites where patients with numerous disorders, including patients with contaminated or infected wounds, are being hospitalized for several days within the same department. From this springs the concern for legal and medical consequences of potential cross-infection as well the surgeons' decisions to initiate antibiotic prophylaxis [25-26]. A similar stereotype holds with regard to avoiding physical effort to prevent recurrence. This opinion, originating from the times when hernias were treated with tension methods, lingers on among surgeons and patients alike. Unfortunately, this results in unnecessary extension of sick leaves thus increasing the social costs of treatment [27].

Guidelines provided by international societies constitute the basic line of defense in the proceedings aimed at explaining any potential adverse events. Compliance with the recommendations usually confirms the due diligence in the treatment process. Unfortunately, every third surgeon declared that the recommendations of scientific societies have no impact on their therapeutic decisions. Numerous discrepancies between the theoretical knowledge and clinical practice suggest that more consideration should be paid to the convergence of these aspects. It appears that systematic training of all surgeons undergoing specialization training would

\section{PIŚMIENNICTWO}

1. Antoniou S.A., Pointner R., Granderath F.A.: Current treatment concepts for groin hernia. Langenbecks Arch. Surg. 2014; 399 (5): 553-558.

2. Beets G.L., Oosterhuis K.J., Go P.M., Baeten C.G., Kootstra G.: Longterm followup (12-15 years) of a randomized controlled trial comparing Bassini-Stetten, Shouldice, and high ligation with narrowing of the internal ring for primary inguinal hernia repair. J. Am. Coll. Surg. 1997; 185: 352-357.

3. Bittner R., Sauerland S., Schmedt C.G.: Comparison of endoscopic techniques vs Shouldice and other open nonmesh techniques for inguinal hernia repair: a meta-analysis of randomized controlled trials. Surg. Endosc. 2005; 19: 605-615.

4. Bolognini S., Orsini V., Grandinetti P.P., Pata F., Sacco R.: Lichtenstein vs. Rutkow-Robbins technique in the treatment of primary inguinal hernia. Analysis of the long term results. Ann. Ital. Chir. 2006; 77: 51-56.

5. Bringman S., Ramel S., Heikkinen T.J., Englund T., Westman B., Anderberg B.: Tension-free inguinal hernia repair: TEP versus mesh-plug versus Lichtenstein: a prospective randomized controlled trial. Ann. Surg. 2003; 237: 142-147.

6. Butters M., Redecke J., Köninger J.: Long-term results of a randomized clinical trial of Shouldice, Lichtenstein and transabdominal preperitoneal hernia repairs. Br. J. Surg. 2007; 94: 562-565.

7. O’Reilly J., Serdén L.: Performance of 10 European DRG systems in explaining variation in resource utilisation in inguinal hernia repair. Health Econ. 2012; 21 Suppl. 2: 89-101.

8. Mitura K., Romańczuk M.: Redundant modifications of Lichtenstein technique in hernia repair - a descriptive study of practicing surgeons in Poland. Videosurgery and other miniinvasive techniques. 2009; 4 (1): 1-5.

9. Simons M.P., Aufenacker T., Bay-Nielsen M. et al.: European Hernia Society guidelines on the treatment of inguinal hernia in adult patients. Hernia. 2009; 13 (4): 343-403.

10. Bittner R., Arregui M.E., Bisgaard T. et al.: Guidelines for laparoscopic (TAPP)

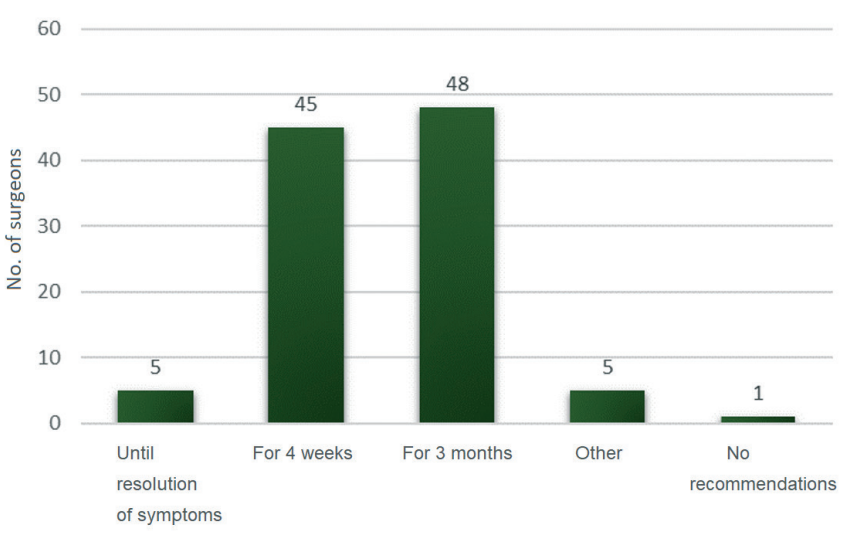

Fig. 5. Type of postoperative recommendations given to patients with regard to the avoidance of physical effort $(n=104)$

provide an excellent opportunity to elucidate numerous aspects of treatment and propagate the current guidelines in this regard [28].

\section{CONCLUSIONS}

The lack of precise numbers and information regarding the types of inguinal hernia repairs in Poland makes impossible to verify the efficacy of treatment and the compliance with the recommendations of scientific societies. Deficiencies within the training system and underfunding are the reasons behind the availability of laparo-endoscopic repairs of inguinal hernias in Poland being too low. The improvement in the surgeons' awareness of inguinal hernia repair techniques along with the availability of appropriately designed trainings may contribute to the improvement of hernia treatment results in Poland. and endoscopic (TEP) treatment of inguinal hernia [International Endohernia Society (IEHS)]. Surg. Endosc. 2011; 25 (9): 2773-2843.

11. Poelman M.M., van den Heuvel B., Deelder J.D. et al.: EAES Consensus Development Conference on endoscopic repair of groin hernias. Surg. Endosc. 2013; 27 (10): 3505-3519.

12. Majumder A., Winder J.S., Wen Y. et al.: Comparative analysis of biologic versus synthetic mesh outcomes in contaminated hernia repairs. Surgery. 2016; 160 (4): 828-838.

13. Collaboration E.H. Mesh compared with non-mesh methods of open groin hernia repair: systematic review of randomized controlled trials. Br. J. Surg. 2000; 87: 854-859.

14. Amato B., Moja L., Panico S. et al.: Shouldice technique versus other open techniques for inguinal hernia repair. Cochrane Database Syst. Rev. 2012; 4: CD001543.

15. Bay-Nielsen M., Kehlet H.: Inguinal herniorrhaphy in women. Hernia 2006; 10: 30-33.

16. Issa N., Ohana G., Bachar G.N. et al.: Long-Term Outcome of Laparoscopic Totally Extraperitoneal Repair of Bilateral Inguinal Hernias with a Large Single Mesh. World J. Surg. 2016; 40 (2): 291-297.

17. Davies B.W., Campbell W.B.: Inguinal hernia repair: see one, do one, teach one? Ann. R. Coll. Surg. Engl. 1995; 77: 299-301.

18. Gholghesaei M., Langeveld H.R., Veldkamp R., Bonjer H.J.: Costs and quality of life after endoscopic repair of inguinal hernia vs open tension-free repair: a review. Surg. Endosc. 2005; 19: 816-821.

19. Butler R.E., Burke R., Schneider J.J., Brar H., Lucha P.A. Jr.: The economic impact of laparoscopic inguinal hernia repair: results of a double-blinded, prospective, randomized trial. Surg. Endosc. 2007; 21: 387-390. 
20. Heikkinen T.J., Haukipuro K., Hulkko A.: A cost and outcome comparison between laparoscopic and Lichtenstein hernia operations in a day-case unit. A randomized prospective study. Surg. Endosc. 1998; 12: 1199-1203.

21. Callesen T., Bech K., Kehlet H.: One-thousand consecutive inguinal hernia repairs under unmonitored local anesthesia. Anesth. Analg. 2001; 93: 1373-1376.

22. Jess P., Hauge C., Hansen C.R.: Long-term results of repair of the internal ring for primary inguinal hernia. Eur. J. Surg. 1999; 165: 748-750.

23. Callesen T., Bech K., Kehlet H.: The feasibility, safety and cost of infiltration anaesthesia for hernia repair. Hvidovre Hospital Hernia Group. Anaesthesia. 1998; 53: 31-35.

24. Seker D., Oztuna D., Kulacoglu H. et al.: Mesh size in Lichtenstein repair: a systematic review and meta-analysis to determine the importance of mesh size.
Hernia. 2013; 17 (2): 167-175.

25. Ferorelli D., Zotti F., Tafuri S.: Good medical practices in the use of antibiotic prophylaxis in a surgery ward: Results of a 2013 Apulian study. Am. J. Infect. Control. 2015; 43 (11): 79-81.

26. Zamkowski M.T., Makarewicz W., Ropel J. et al.: Antibiotic prophylaxis in open inguinal hernia repair: a literature review and summary of current knowledge. Videosurgery and other miniinvasve techniques. 2016;11 (3): 127-136.

27. Callesen T., Klarskov B., Bech K., Kehlet H.: Short convalescence after inguinal herniorrhaphy with standardised recommendations: duration and reasons for delayed return to work. Eur. J. Surg. 1999; 165: 236-241.

28. De Turris S.V., Cacchione R.N., Mungara A., Pecoraro A., Ferzli G.S.: Laparoscopic herniorrhaphy: beyond the learning curve. J. Am. Coll. Surg. 2002; 194: 65-73.

Word count: $3000 \quad$ Page count: $7 \quad$ Tables: $4 \quad$ Figures: 5 References: 28

DOI: $\quad 10.5604 / 01.3001 .0010 .5406$

Table of content: https://ppch.pl/resources/html/articlesList?issueld=10478

Copyright: Copyright @ 2017 Fundacja Polski Przegląd Chirurgiczny. Published by Index Copernicus Sp. z o. o. All rights reserved.

Competing interests: The authors declare that they have no competing interests.

2 The content of the journal "Polish Journal of Surgery" is circulated on the basis

- of the Open Access which means free and limitless access to scientific data.

Corresponding author:

Cite this article as:

This material is available under the Creative Commons - Attribution 4.0 GB. The full terms of this license are available on: http://creativecommons.org/licenses/by-nc-sa/4.0/legalcode

Dr n. med. Kryspin Mitura; Department of General Surgery, Municipal Hospital in Siedlce; Tel.: +48 602809 035; E-mail: chirurgia.siedlce@gmail.com

Mitura K., Dąbrowiecki S., Śmietański M., Matyja A.; Do we need changes in the organization of training in the hernia treatment in Poland? A survey on the acknowledgment of the recommendations of international hernia societies by surgeons; Pol Przegl Chir 2017: 89 (4):12-18 